\title{
DETERMINATION OF THE MINIMAL AMOUNT OF WATER FOR EFFECTIVE SUPPRESSION OF THE THERMAL DECOMPOSITION OF FOREST COMBUSTIBLE MATERIALS
}

\author{
Alena O. Zhdanova ${ }^{1,{ }^{*}}$, Galina S. Nyashina ${ }^{1}$, and Maria M. Osmolovskaya ${ }^{1}$ \\ ${ }^{1}$ National Research Tomsk Polytechnic University, 634050 Tomsk, Russia
}

\begin{abstract}
Forest fires are big problem for whole the world community. The development of new effective methods is needed to increase the efficiency of the firefighting. We have investigated experimentally the suppression of thermal decomposition of different typical forest combustibles using water aerosol. Droplet sizes were $0.02-0.2 \mathrm{~mm}$; the concentration $-3.8 \cdot 10^{-5} \mathrm{~m}^{3}$ of water $/ \mathrm{m}^{3}$, the flow rate $-0.00035 \mathrm{l} / \mathrm{s}$, flow velocity $-2 \mathrm{~m} / \mathrm{s}$. Registration of the aerosol propagation and interaction with combustibles was done by high-speed video camera using Shadow Photography and Particle Tracking Velocimetry methods. The effective water volumes for fire suppression were determined together with corresponding suppression times. The obtained results could be used for improvement of the fire-fighting technologies.
\end{abstract}

\section{Introduction}

Forest fires are sharp problem for whole the world community [1-3]. Determination of the minimal effective water volume for optimal fire-fighting is the key problem in this area. Hundreds or even thousands tons of water are usually needed for suppression of forest fire. However the usage of greater and greater water amounts does not correspond to acceleration of the forest fire suppression. There are some recommendations about water atomization before injection into the fire site to cover widest area. Though there is not an effective realization of the proposed ideas still.

The aim of this work is experimental determination of the minimal water amount that is enough for effective suppression of the thermal decomposition of forest combustible materials (FCM) during pre-defined time interval.

\footnotetext{
${ }^{*}$ Corresponding author: zhdanovaao@tpu.ru
} 


\section{The methods and the experimental setup}

The scheme of the experimental setup is shown at fig. 1. The experiments were done in two stages. At the first one we have registered the details of parching of the model fire sites for each type of investigated FCM with determination of characteristic times $t_{\mathrm{b}}$. At the second one, we have measured the fire suppression times $t_{\mathrm{e}}$ for model fire sites.

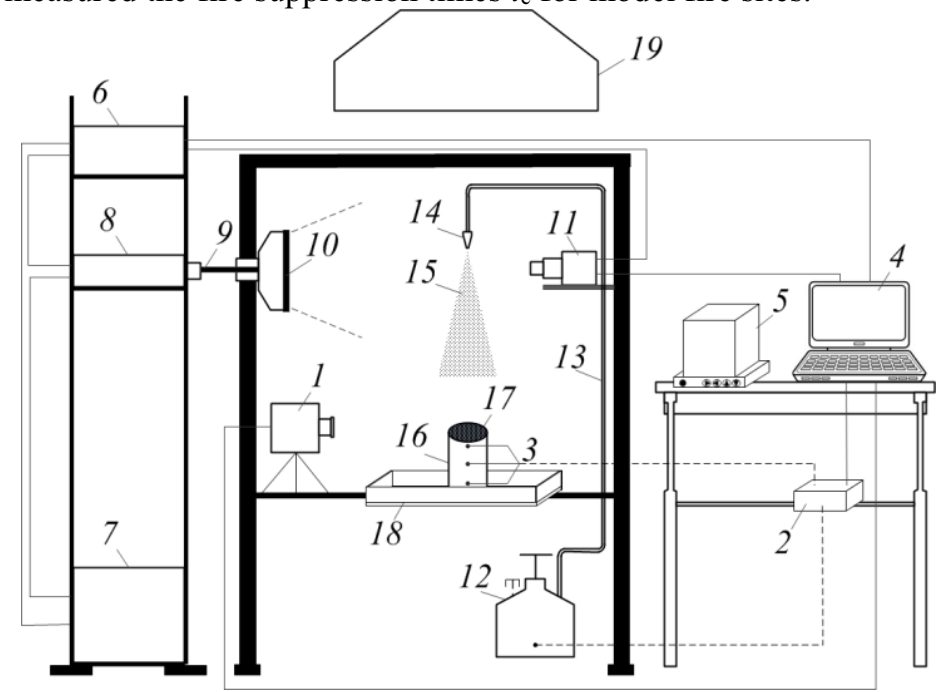

Fig. 1. Scheme of experimental setup: 1 - high-speed camera; 2 - high-speed analog input module; 3 - thermocouples; 4 - workstation (PC); 5 - laboratory microbalance; 6 - signal synchronizer; 7 laser generator; 8 - solid double-pulse laser; 9 - optical fiber; 10 - diffuse screen; 11 - crosscorrelation camera; 12 - container with water; 13 - water supply channel; 14 - spray nozzle; 15 water mist; 16 - cylinder with forest fuel; 17 - forest fuel; 18 - metal tray; 19 - exhaust ventilation.

Four types of typical FCM were used during experiments: the birch leaves, spruce needles, aspen branches and the mix of them (with mass ratios $25 \%, 15 \%$ and $60 \%$ ).

The first stage includes following steps:

- the cylinder 17 with portion of the FCM was installed onto fire-resisting tray 19;

- The needle-shape thermocouples 3 (K-type, with working range 223-1473 K, bias \pm 3 $\mathrm{K}$ andtime lag less than $1 \mathrm{~s}$ ) were placed at three points on the symmetry axe of the cylinder 17 ;

- The time count was started from the moment of the ignition of the model fire site (with precision $0.01 \mathrm{~s}$ );

- The time gap between ignition and the moment of temperature decrease lower than the thermal decomposition threshold $\left(T_{\mathrm{f}} \approx 370 \mathrm{~K}\right)$ for all three thermocouples was estemated as total parching time $t_{\mathrm{b}}$ for chosen type of the FCM [4-6]. The stable exceed of the layer temperature above mentioned threshold was assumed as stable combustion of the FCM.

The second stage of the experiment (namely extinguishing of the fire site) consists of water aerosol feeding to the FCM portion surface. The water atomization was done by system consisting of nozzle 14 , tank for pressurized water 12 and supporting fittings 13 . The water feeding was started in 10-15 s after ignition (this time is enough for establishment of the thermal decomposition at whole the FCM portion). The water aerosol feeding was supported up to the moment of the total extinguishing of the model fire site.

The water droplet sizes were controled by the optical diagnostic system [7] using "Shadow Photography" (SP) method. The droplet velocities were measured by the same system using "Particle Tracking Velocimetry" (PTV) method [8]. 
We assumed that the thermal decomposition of the FCM is started if the temperature measured by one of the thermocouples (which are installed at different heights of the FCM portion) was exceeding $370 \mathrm{~K}$. The end of the thermal decomposition was assumed to the moment when the temperature of all the thermocouples become lower than $370 \mathrm{~K}$ that is lower than active pyrolysis threshold $T_{\mathrm{ef}}=370 \mathrm{~K}$. The fig. 2 shows typical views of the FCM portions during the experiment: initial state, active combustion, at the fire extinction and after the fire extinguishing by the water aerosol.

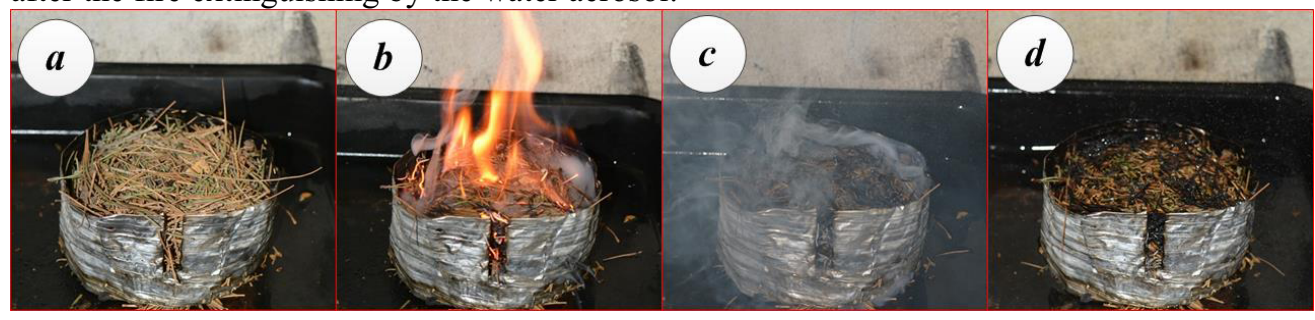

Fig. 2. Typical states of the spruce needles portion during the simulation fo the forest fire extinguishing by aerosol flow (the layer thickness is $h_{\mathrm{f}}=40 \mathrm{~mm}$, diameter $d_{\mathrm{f}}=100 \mathrm{~mm}$ ). The states are: $a$-initial; $b$-during the active combustion; $c$-during the extinguishing; $d$-after the total fire extinction.

The water residue at the tray 19 (under the FCM portion) was collected after each experiment for analysis of its volume $V_{\mathrm{s}}$. The water amount used for fire extinction was calculated by formula (1):

$$
V_{\mathrm{w}}=\mu_{\mathrm{w}} \cdot t_{\mathrm{e}}-V_{\mathrm{s}} .
$$

where $\mu_{\mathrm{w}}$. is water flow rate and $t_{\mathrm{e}}$ is fire extinction time. There were 15-20 experiments done for each type and certain portion of the FCM. The results $\left(t_{\mathrm{b}}\right.$ or $t_{\mathrm{e}}$, values measured for identical samples) which differ from the average value for more than $5 \%$ were excluded from the consideration.

Systematic errors for main parameters were: droplet size $\left(R_{\mathrm{d}}\right)-7 \cdot 10^{-6} \mathrm{~m}$, droplet velocity $\left(U_{\mathrm{d}}\right)-3.4 \%$, times $t_{\mathrm{e}}$ and $t_{\mathrm{b}}-0.5 \mathrm{~s}$, volume $V_{\mathrm{e}}-5 \cdot 10^{-4} 1$. The random errors of the temperature $\left(T_{\mathrm{f}}\right)$ measurements were less than $30 \mathrm{~K}$.

\section{Results and discussion}

The table 1 shows the dependencies of the thermal decomposition suppression time on FCM portion diameter. The times of the total parching of the FCM sample without fire extinction efforts are presented too.

Table 1. The dependencies of the FCM parching time $\left(t_{\mathrm{b}}\right)$ and thermal decomposition suppression time $\left(t_{\mathrm{e}}\right)$ on the FCM portion diameter (for fixed portion height $h_{\mathrm{f}} \approx 40 \mathrm{~mm}$ ).

\begin{tabular}{|c|c|c|c|c|c|c|c|c|}
\hline \multirow{2}{*}{$\boldsymbol{d}_{\mathbf{f}, \mathbf{m}} \mathbf{m}$} & \multicolumn{2}{|c|}{ birch leaves } & \multicolumn{2}{c|}{ spruce needles } & \multicolumn{2}{c|}{ aspen branches } & \multicolumn{2}{c|}{ mixed FCM } \\
\cline { 2 - 9 } & $\boldsymbol{t}_{\mathbf{b}}$ & $\boldsymbol{t}_{\mathbf{e}}$ & $\boldsymbol{t}_{\mathbf{b}}$ & $\boldsymbol{t}_{\mathbf{e}}$ & $\boldsymbol{t}_{\mathbf{b}}$ & $\boldsymbol{t}_{\mathbf{e}}$ & $\boldsymbol{t}_{\mathbf{b}}$ & $\boldsymbol{t}_{\mathbf{e}}$ \\
\hline 0.02 & 103.3 & 33.5 & 159.7 & 6.2 & 382.4 & 14.2 & 134.7 & 17.0 \\
\hline 0.04 & 147.7 & 72.0 & 192.2 & 10.9 & 407.3 & 24.3 & 194.4 & 36.9 \\
\hline 0.06 & 189.6 & 109.1 & 228.9 & 19.3 & 463.2 & 41.5 & 258.3 & 57.5 \\
\hline 0.08 & 229.0 & 144.8 & 267.0 & 34.3 & 550.1 & 71.1 & 326.4 & 78.6 \\
\hline 0.1 & 266.1 & 179.0 & 315.2 & 60.7 & 668.1 & 121.6 & 398.7 & 100.4 \\
\hline 0.12 & 300.8 & 211.80 & 364.7 & 107.6 & 817.2 & 208.2 & 475.2 & 122.6 \\
\hline 0.14 & 333.0 & 243.2 & 418.4 & 190.7 & 997.3 & 356.2 & 555.9 & 145.5 \\
\hline
\end{tabular}


It is shown that the FCM total parching times $t_{\mathrm{b}}$ are much longer than fire extinction times $t_{\mathrm{e}}$. It means that water aerosol can be effective tool for forest fire suppression.

The remarkable parameter of the fire extinction efficiency is the water consumption for the chosen method. Table 2 demonstrate the dependence of the water amount used for the model fire site extinguishing on the FCM portion volume $V_{\mathrm{f}}$. These dependencies were obtained by generalization of the experimental data when FCM portion height $\left(h_{\mathrm{f}}\right)$ was in range from $40 \mathrm{~mm}$ to $100 \mathrm{~mm}$ and the portion diameter $d_{\mathrm{f}}$ from $20 \mathrm{~mm}$ to $80 \mathrm{~mm}$, that is for ranges when the irrigation density $\xi_{\mathrm{f}}$ has relatively low influenceonto the experimental results. The thermal effect of the burning layer has the definitive influence at this case.

Table 2. The dependence of water consumption $\left(V_{\mathrm{w}}, 1\right)$ on the FCM portion volume $\left(V_{\mathrm{f}}, \mathrm{m}^{3}\right)$.

\begin{tabular}{|c|c|c|c|c|}
\hline $\boldsymbol{V}_{\mathbf{f}}, \mathbf{m}^{\mathbf{3}}$ & birch leaves & spruce needles & aspen branches & mixed FCM \\
\hline 0.0002 & 0.004 & 0.003 & 0.005 & 0.01 \\
\hline 0.0004 & 0.007 & 0.005 & 0.011 & 0.015 \\
\hline 0.0006 & 0.014 & 0.013 & 0.02 & 0.019 \\
\hline 0.0008 & 0.023 & 0.021 & 0.034 & 0.025 \\
\hline 0.001 & 0.036 & 0.035 & 0.05 & 0.03 \\
\hline
\end{tabular}

It was shown that the growth of the FCM layer thickness $h_{\mathrm{f}}$ from $40 \mathrm{~mm}$ to $100 \mathrm{~mm}$ leads to growth of the $V_{\mathrm{e}}$ for not more than 50-60\%. The growth of the model fire site diameter $d_{\mathrm{f}}$ from $20 \mathrm{~mm}$ to $60 \mathrm{~mm}$ leads to essential growth (for 3-4 times) of the $V_{\mathrm{w}}$.

The analysis of table 2 allows to estimate the water volumes needed for effective suppression of the FCM decomposition for surfaces which are much higher than were used in our experiments. It was shown that $1 \mathrm{~m}^{2}$ of the spruce needles needs in 0.71 of water aerosol, the birch leaves needs $-0.85 \mathrm{l} / \mathrm{m}^{2}$ and mixed FCM needs $0.9 \mathrm{l} / \mathrm{m}^{2}$. Together with this the traditional techniques needs from $2-3 \mathrm{l} / \mathrm{m}^{2}$ to $8-10 \mathrm{l} / \mathrm{m}^{2}$.

\section{Acknowledgments}

The investigation was supported by Russian Science Foundation (project 14-39-00003).

\section{References}

1. X.K. Xiao, B.H. Cong, X.S. Wang, K.Q. Kuang, Richard K.K. Yuen, G.X. Liao, J. Fire Sci. 29, 4 (2011)

2. S. McAllister, Fire Saf. J. 61 (2013)

3. S. McAllister, I. Grenfell, A. Hadlow, W.M. Jolly, M. Finney, J. Cohen, Fire Saf. J. 51 (2012)

4. A.M. Grishin, Mathematical modeling of forest fire and new methods of fighting them (Publishing House of Tomsk State University, Tomsk, 1997)

5. A.M. Grishin, S.P. Sinitsyn, I.V. Akimova, Combust. Explosion Phys. J. 27 (1991)

6. C.H. Lautenberger, C.A. Fernando-Pello, Combust Flame 156 (2009)

7. R.S. Volkov, G.V. Kuznetsov, P.A. Strizhak, Int. J. Therm. Sci. 88 (2015)

8. Y. Hagiwara, S. Sakamoto, M. Tanaka, K. Yoshimura Exp. Therm. Fluid Sci. 26, 2-4 (2002) 